\title{
Recombinant human deoxyribonuclease for the treatment of acute asthma in children
}

\author{
R Boogaard, ${ }_{1}^{1}$ F Smit, ${ }^{2}$ R Schornagel, ${ }^{3}$ A A P H Vaessen-Verberne, ${ }^{4} \mathrm{~J}$ M Kouwenberg, ${ }^{5}$ \\ M Hekkelaan, ${ }^{6}$ T Hendriks, ${ }^{7}$ S W W Feith, ${ }^{8}$ W C J Hop, ${ }^{9}$ J C de Jongste, ${ }^{1}$ \\ P J F M Merkus ${ }^{1,10}$
}

${ }^{1}$ Department of Pediatric Pulmonology, Erasmus MCSophia Children's Hospital, Rotterdam, The Netherlands; ${ }^{2}$ Department of Pediatrics, Medisch Centrum Rijnmond Zuid, Rotterdam, The Netherlands; ${ }^{3}$ Department of Pediatrics, Albert Schweitzer Hospital, Dordrecht, The Netherlands: ${ }^{4}$ Department of Pediatrics, Amphia Hospital, Breda, The Netherlands:

${ }^{5}$ Department of Pediatrics, HagaTeaching Hospital/Juliana Children's Hospital, The Hague The Netherlands; ${ }^{6}$ Department of Pediatrics, Reinier de Graaf Gasthuis, Delft, The Netherlands: ${ }^{7}$ Department of Pediatrics, Catharina Hospital, Eindhoven, The Netherlands:

${ }^{8}$ Department of Pediatrics, Sint Franciscus Gasthuis, Rotterdam, The Netherlands; ${ }^{9}$ Department of Epidemiology and

Biostatistics, Erasmus MC

Rotterdam, The Netherlands;

${ }^{10}$ Department of Pediatrics, Division of Respiratory Medicine, Radboud University, Nijmegen Medical Centre, Nijmegen, The Netherlands

Correspondence to:

Dr R Boogaard, Room Sb-2666,

Department of Pediatric

Pulmonology, Erasmus MC-

Sophia Children's Hospital

Rotterdam, P O Box 2060, 3000

CB Rotterdam, The Netherlands;

r.boogaard@erasmusmc.nl

Received 23 March 2007

Accepted 12 June 2007

Published Online First

2 August 2007

\begin{abstract}
Background: Airway obstruction in acute asthma is the result of airway smooth muscle contraction, inflammation and mucus plugging. Case reports suggest that mucolytic therapy might be beneficial in acute asthma. The aim of this study was to determine the efficacy of the mucolytic drug recombinant human deoxyribonuclease (rhDNase) in addition to standard treatment at the emergency department in children with an asthma exacerbation.

Methods: In a multicentre randomised double-blind controlled clinical trial, 121 children brought to the emergency room for a moderate to severe asthma exacerbation were randomly assigned to receive either a single dose of $5 \mathrm{mg}$ nebulised rhDNase or placebo following the second dose of bronchodilators. An asthma score (scale 5-15) was assessed at baseline and at 1, 2, 6,12 and $24 \mathrm{~h}$. The primary outcome variable was the asthma score $1 \mathrm{~h}$ after the study medication.
\end{abstract}

Results: One hour after the study medication the asthma score in the rhDNase group showed an adjusted mean decrease from baseline of 1.0 (95\% Cl 0.5 to 1.6$)$ points compared with $0.7(95 \% \mathrm{Cl} 0.3$ to 1.2$)$ points in the placebo group (mean difference $0.4(95 \% \mathrm{Cl}-0.2$ to 1.0$)$ points; $p=0.23$ ). The asthma score over the study period of $24 \mathrm{~h}$ also did not differ significantly between the rhDNase and placebo group (mean difference $0.2(95 \% \mathrm{Cl}$ -0.3 to 0.7 ) points, $p=0.40$ ). The duration of oxygen supplementation and number of bronchodilator treatments in the first $24 \mathrm{~h}$ were similar in both groups.

Conclusion: Adding a single dose of nebulised rhDNase to standard treatment in the emergency room has no beneficial effects in children with moderate to severe acute asthma.

The standard treatment for children with acute asthma consists of frequent nebulised bronchodilators and early systemic corticosteroid therapy. ${ }^{1}$ Since airway obstruction by viscous mucus is one of the pathophysiological features of acute asthma, ${ }^{2-4}$ a logical approach to treatment might be to use a mucolytic agent. It is the DNA present in mucous plugs following lysis of inflammatory cells that contributes to increased viscosity and adhesiveness of the mucus, ${ }^{5}$ and free DNA was indeed noted in the mucus of subjects with acute asthma. ${ }^{6}$ Such mucus can be liquefied by recombinant human deoxyribonuclease (rhDNase; dornase alfa) which cleaves extracellular DNA. ${ }^{78}$ The efficacy of rhDNase has been well documented in patients with cystic fibrosis, ${ }^{9}$ and several publications suggest that it is also effective in children with severe acute asthma with ${ }^{10-12}$ or without atelectasis. ${ }^{11} 13$
We performed a randomised controlled trial to determine whether nebulised rhDNase added to standard treatment would improve symptoms in children with moderate to severe acute asthma.

\section{METHODS}

\section{Patients}

Eligible subjects for this study were children aged 2-18 years with symptoms of acute asthma whose asthma score (table 1) at arrival in the emergency room was $\geqslant 8$ and who required at least two treatments with nebulised bronchodilators. We did not include children with other causes of dyspnoea, a chronic cardiopulmonary disease other than asthma or those with a neurological condition.

\section{Study design}

This was a multicentre double-blind parallel-group randomised study comparing the effect of inhaled rhDNase with placebo on the asthma score in children aged 2-18 years with symptoms of acute asthma. The trial was carried out in emergency rooms of eight participating hospitals in the Netherlands between September 2005 and October 2006. The study was approved by the ethics review boards of all eight centres and written parental informed consent was obtained for each child.

All children received a dose of nebulised bronchodilators on arrival ( $<4$ years old: $2.5 \mathrm{mg}$ salbuta$\mathrm{mol}, 0.25 \mathrm{mg}$ ipratropium; $\geqslant 4$ years old: $5 \mathrm{mg}$ salbutamol, $0.5 \mathrm{mg}$ ipratropium). After parental consent, patients were randomly assigned to receive a single nebulisation of $5 \mathrm{mg}$ rhDNase ( $5 \mathrm{ml}$ solution of $1 \mathrm{mg} / \mathrm{ml} \mathrm{rhDNase;} \mathrm{Roche,} \mathrm{Basel,}$ Switzerland) or $5 \mathrm{mg}$ placebo (5 ml sodium chloride $0.9 \%$ ) following the second nebulisation of bronchodilators (fig 1). We opted for a dose of $5 \mathrm{mg}$ in anticipation of the expected suboptimal lung deposition in young children with airways obstruction due to asthma. Study medication was prepared by the hospital pharmacists and had identical appearance and aroma. The vials with study medication were stored in a refrigerator located in the emergency department.

Study medication was administered with the use of a jet nebuliser using a mouthpiece when possible or through a firmly applied facemask at a constant oxygen supply rate of 6-8 $1 / \mathrm{min}$ from a wall outlet. The same nebulising equipment (Pari LC Star, Pari $\mathrm{GmbH}$, Germany) was used in all participants.

Randomisation was carried out in the hospital pharmacies of the participating hospitals using a 
Table 1 Methods of calculating the asthma score and the severity of asthma*

\begin{tabular}{|c|c|c|c|}
\hline \multirow[b]{2}{*}{ Variable } & \multicolumn{3}{|l|}{ Asthma scoring } \\
\hline & 1 point & 2 points & 3 points \\
\hline \multicolumn{4}{|c|}{ Respiratory rate (breaths/min) } \\
\hline $2-3$ years & $\leqslant 34$ & $35-39$ & $\geqslant 40$ \\
\hline $4-5$ years & $\leqslant 30$ & $31-35$ & $\geqslant 36$ \\
\hline $6-12$ years & $\leqslant 26$ & $27-30$ & $\geqslant 31$ \\
\hline$>12$ years & $\leqslant 23$ & $24-27$ & $\geqslant 28$ \\
\hline Haemoglobin saturation & $>95 \%$ with room air & $\begin{array}{l}90-95 \% \text { with room air or } \\
\geqslant 90 \% \text { with supplemental } \\
\text { oxygen }\end{array}$ & $\begin{array}{l}<90 \% \text { with room air or } \\
\text { supplemental oxygen }\end{array}$ \\
\hline Auscultation & $\begin{array}{l}\text { Normal breathing or end- } \\
\text { expiratory wheezing }\end{array}$ & Expiratory wheezing & $\begin{array}{l}\text { Inspiratory and expiratory } \\
\text { wheezing, diminished breath } \\
\text { sounds, or both }\end{array}$ \\
\hline Retractions & None or intercostal & Intercostal and substernal & $\begin{array}{l}\text { Intercostal, substernal and } \\
\text { supraclavicular }\end{array}$ \\
\hline \multirow[t]{3}{*}{ Dyspnoea } & $\begin{array}{l}\text { Speaks in sentences or } \\
\text { coos and babbles }\end{array}$ & $\begin{array}{l}\text { Speaks in partial sentences } \\
\text { or utters short cries }\end{array}$ & $\begin{array}{l}\text { Speaks in single words or short } \\
\text { phrases or grunts }\end{array}$ \\
\hline & Severity of asthma & & \\
\hline & Mild & Moderate & Severe \\
\hline Asthma score & $5-7$ & $8-11$ & $12-15$ \\
\hline
\end{tabular}

*The overall asthma score (scale 5-15 points) was calculated by adding the scores for each of the following five variables: respiratory rate, haemoglobin saturation, auscultation, retractions and dyspnoea. ${ }^{14}$

random table sample with blocks of four numbers prepared by the study statistician. Throughout the study, physicians, nurses, parents and the trial coordinator remained unaware of the treatment assignment.

The dosing interval of nebulised bronchodilators was determined by the attending physician based on symptom severity and clinical improvement rate. Systemic corticosteroids (1 $\mathrm{mg} / \mathrm{kg}$ prednisolone as a starting dose and subsequently 1$2 \mathrm{mg} / \mathrm{kg}$ /day for $5-7$ days to a maximal dose of $60 \mathrm{mg} /$ day) were given after the second dose of bronchodilators according to Dutch national asthma guidelines.

On the child's arrival at the emergency department (TA) the attending physician recorded the clinical history (including previous admissions for asthma, duration and possible triggers of the current symptoms) and medication use. Vital signs, the need for supplemental oxygen and the asthma score were also assessed at TA and again just before nebulisation of the second dose of bronchodilators that was followed by the single dose of study medication (T0). The asthma score was subsequently assessed at $1 \pm 0.25 \mathrm{~h}$ (T1), $2 \pm 0.5 \mathrm{~h}$ (T2), $6 \pm 1 \mathrm{~h}$ (T6), $12 \pm 2 \mathrm{~h}$ (T12) and $24 \pm 2 \mathrm{~h}$ (T24) after nebulisation of the study medication (fig 1). Supplemental oxygen was started when haemoglobin saturation was consistently lower than $93 \%$ and was stopped when saturation was consistently above $92 \%$. The total number of nebuliser treatments in the first $24 \mathrm{~h}$ after the study medication, time until discharge and duration of oxygen supplementation were recorded.

The decision to admit or discharge the child was up to the discretion of the treating physician. If the child was discharged home from the emergency department or within $24 \mathrm{~h}$ after admission, the researcher reported 3-5 days later whether any subsequent visits had been made to a medical facility within $72 \mathrm{~h}$ after the initial presentation.

\section{Efficacy end points}

The primary outcome measure was the asthma score $1 \mathrm{~h}$ after the study medication. We used the asthma score developed by Qureshi and colleagues ${ }^{14}$ in which respiratory rate, haemoglobin saturation, auscultatory findings, retractions and dyspnoea are scored on a 3-point scale, yielding a total score ranging from 5 (mild) to 15 (severe) (table 1). A previous study showed good inter-rater reliability of this asthma score (Pearson correlation

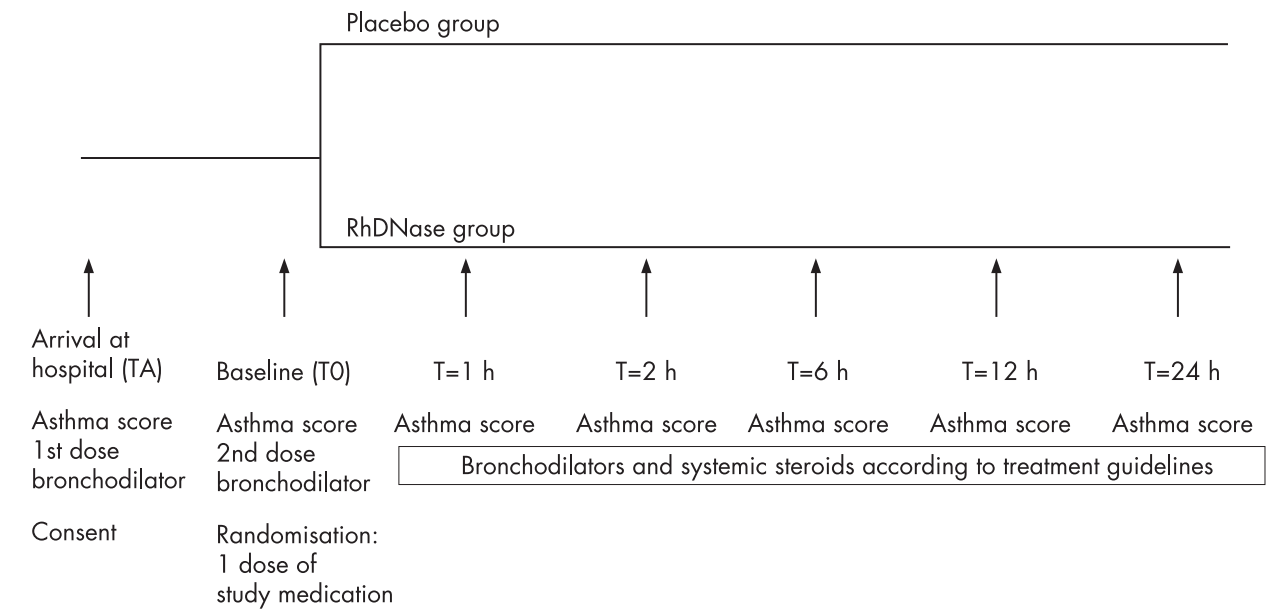

Figure 1 Study design. 
Figure 2 Enrolment, random assignment, follow-up and analysis.

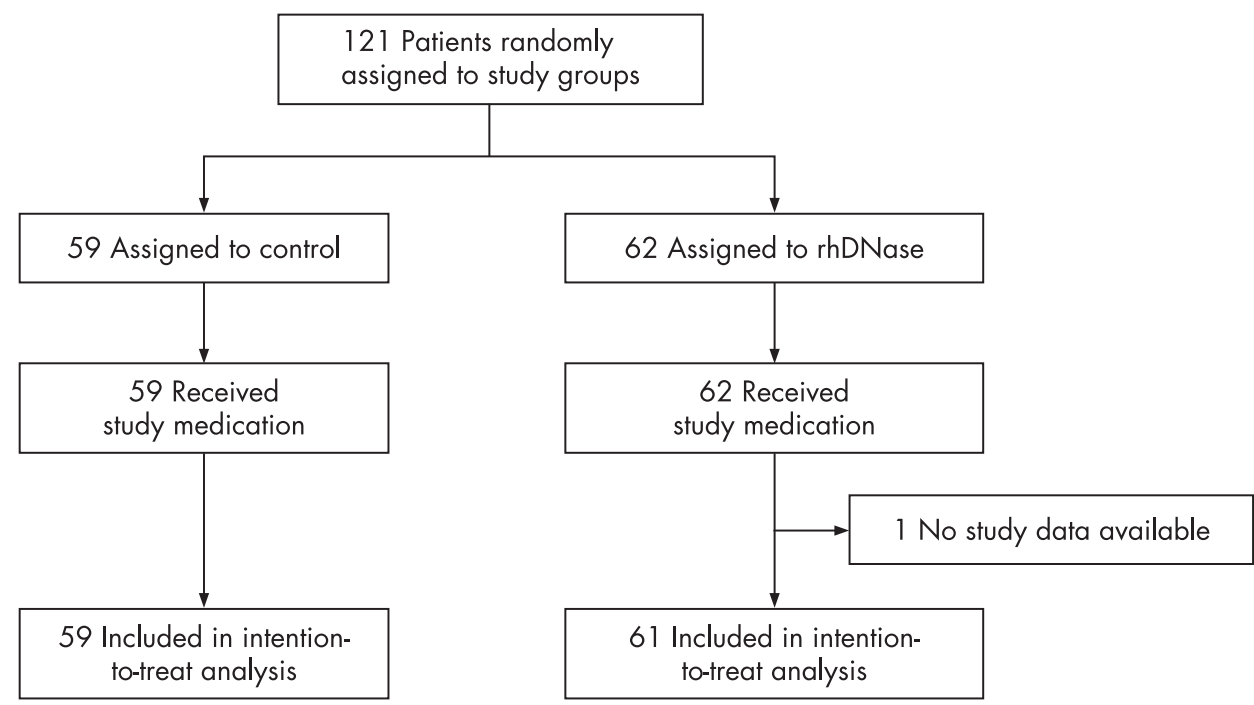

statistic 0.92). ${ }^{14}$ The asthma score had been introduced as a clinical tool in all participating centres before the start of the study, so all participating physicians were experienced in using the score.

The secondary outcome measures were the mean asthma scores at 2, 6, 12 and $24 \mathrm{~h}$ after the study medication, need for hospital admission, duration of admission, duration of supplemental oxygen and the number of nebuliser treatments in the first $24 \mathrm{~h}$.

\section{Estimate of sample size}

In a pilot study of 26 children the mean (SD) asthma score decreased 0.8 (1.4) points between the time points T0 (before the second dose of bronchodilators) and T1 ( $1 \mathrm{~h}$ after the second dose of bronchodilators). To demonstrate an additional decrease of 0.8 points at $\mathrm{T} 1$ at a $5 \%$ significance level for a two-sided test with $80 \%$ power would require 100 patients $(50$ children in each group).

\section{Statistical analysis}

Data were analysed on an intention-to-treat basis. Differences between baseline group characteristics and secondary outcome measures were assessed by $\chi^{2}$ or Fisher exact tests and the Mann-Whitney test, as appropriate. Main analyses of betweengroup comparisons regarding asthma score changes were performed by repeated measures of analysis of variance (RmANOVA) with baseline (T0) asthma score, age, sex and study centre as covariates. In calculating mean values of the asthma score, the individual asthma score after discharge was arbitrarily set at 5 points. Linear interpolation of the asthma score was used if scores had been assessed outside the prespecified time range. Linear interpolation was also used when the item "dyspnoea" could not be assessed accurately because the child was asleep at the time of observation. The analysis was performed with SPSS software Version 11.5 and SAS PROC MIXED. For all the analyses, a two-tailed $p$ values of $<0.05$ was considered to indicate statistical significance.

\section{RESULTS}

A total of 121 children were enrolled and randomly assigned to treatment groups: 62 to rhDNase and 59 to placebo (fig 2).
There was no difference in the demographic and baseline clinical characteristics of the two groups (table 2).

All children were treated with a dose of nebulised bronchodilators on arrival in the emergency department. Overall, the asthma score decreased after this first nebuliser treatment by a mean of 1.55 (95\% CI 1.32 to 1.79 ) points (fig 3). The study medication in the rhDNase group was given a median of $1.3 \mathrm{~h}$ (interquartile range (IOR) 1.0-2.0) after arrival and in the

\section{Primary end point}

Both groups showed a similar improvement in the asthma score during the first $24 \mathrm{~h}$ (fig 3). At baseline, the mean asthma score was 10.2 in the rhDNase-treated group and 10.4 in the placebo group. One hour after nebulisation of the study medication the asthma score in the rhDNase group showed an adjusted mean decrease of $1.0(95 \%$ CI 0.5 to 1.6$)$ points from baseline compared with 0.7 (95\% CI 0.3 to 1.2$)$ points in the placebo group (mean difference 0.4 (95\% CI -0.2 to 1.0 ) points; $\mathrm{p}=0.23)$.

Overall, compared with baseline, the asthma score $1 \mathrm{~h}$ after the study medication had improved in 72 children ( 37 in the rhDNase group, 35 in the placebo group), had not changed in 21 (12 rhDNase, 9 placebo) and had worsened in 27 children (12 rhDNase, 15 placebo); $p=0.68$.

Repeated measures analysis of variance showed no significant difference between the groups in the asthma score over the whole period of $24 \mathrm{~h}$ : the adjusted mean decrease was 4.1 (95\% CI 3.6 to 4.6) points in the rhDNase group and 3.9 (95\% CI 3.3 to 4.5 ) points in the placebo group (mean difference 0.2 (95\% CI -0.3 to 0.7 ) points; $p=0.40$ ).

The item "dyspnoea" of the asthma score could not be assessed accurately in some children who were asleep at the time of the observation. In these cases, linear interpolation of the item "dyspnoea" was used in order to obtain a total asthma score. An analysis in which the interpolated asthma scores of sleeping children were not included showed similar results (data not shown).

\section{Subgroup analyses}

There was no significant effect modification by baseline asthma score, age or the use of anti-inflammatory medication prior to placebo group after $1.3 \mathrm{~h}$ (IOR 1.0-1.8) ( $\mathrm{p}=0.95)$. 
Table 2 Baseline characteristics of the children on arrival at the emergency department

\begin{tabular}{|c|c|c|}
\hline Characteristic & $\begin{array}{l}\text { rhDNase } \\
(\mathrm{N}=61)^{*}\end{array}$ & $\begin{array}{l}\text { Placebo } \\
\text { ( } N=59 \text { ) }\end{array}$ \\
\hline $\operatorname{Sex}(M / F)$ & $40 / 21$ & $37 / 22$ \\
\hline Age (years) & $4.4(2.0-16.3)$ & $4.5(2.1-15.4)$ \\
\hline \multicolumn{3}{|l|}{ Duration of symptoms (n (\%) of patients) } \\
\hline$<12 \mathrm{~h}$ & $19(31)$ & $19(32)$ \\
\hline $12-24 \mathrm{~h}$ & $29(48)$ & $29(49)$ \\
\hline$>24 \mathrm{~h}$ & $13(21)$ & $11(19)$ \\
\hline \multicolumn{3}{|l|}{ Current asthma medication, (n (\%) of patients) } \\
\hline No medication & $17(28)$ & $11(19)$ \\
\hline Short-acting $\beta_{2}$ agonist only & $19(31)$ & $25(42)$ \\
\hline Corticosteroid & $24(39)$ & $22(37)$ \\
\hline Combination (steroid + long-acting $\beta_{2}$ agonist) & $7(11)$ & $6(10)$ \\
\hline Leucotriene antagonist & $3(5)$ & $1(2)$ \\
\hline Systemic corticosteroïd & $2(3)$ & $2(3)$ \\
\hline \multicolumn{3}{|l|}{ Asthma score (scale 5-15) } \\
\hline Arrival at hospital (TA) & $12(8-15)$ & $12(8-15)$ \\
\hline Baseline (TO) & $10(5-14)$ & $10(7-15)$ \\
\hline \multicolumn{3}{|l|}{ Severity of asthma (n (\%) of patients) } \\
\hline \multicolumn{3}{|l|}{ TA: } \\
\hline Severe (score 12-15) & $37(61)$ & $33(57) \dagger$ \\
\hline Moderate (score 8-11) & $24(39)$ & $25(43) \dagger$ \\
\hline \multicolumn{3}{|l|}{ TO: } \\
\hline Severe (score 12-15) & $18(30)$ & $17(29)$ \\
\hline Moderate (score 8-11) & $38(62)$ & $38(64)$ \\
\hline Mild (score 5-7) & $5(8)$ & $4(7)$ \\
\hline
\end{tabular}

Data expressed as median (range) unless otherwise specified.

$\mathrm{TA}$, arrival at the emergency department; TO, before nebulisation of the second dose of bronchodilators and the subsequent single dose of study medication.

*Study data were not available for one of 62 patients in the rhDNase group.

$\uparrow$ The asthma score at arrival (TA) was missing for one patient in the placebo group.

the asthma attack. A separate analysis of the subgroup of children with a severe asthma score $(\geqslant 12)$ at baseline $(n=35)$ also showed no significant difference in the asthma score over time between the rhDNase group and the placebo group (mean difference $-0.1(95 \% \mathrm{CI}-1.3$ to 1.1$) ; \mathrm{p}=0.85)$.

\section{Secondary end points}

\section{Need for hospital admission}

Most of the children (88\%) were admitted to hospital. Only 14 children ( 6 in the rhDNase group, 8 in the placebo group) were discharged home from the emergency department. Four of the admitted children (4\%) required intensive care (2 in the $\mathrm{rhDNase}$ group, 2 in the placebo group).

Thirty-one children were discharged within $24 \mathrm{~h}$ of study entry (14 in the rhDNase group, 17 in the placebo group). Three of those in the placebo group were readmitted to hospital within $72 \mathrm{~h}$ of discharge because symptoms had worsened (1 child after 1 day, 2 children within 1.5 h of discharge) compared with none in the rhDNase group $(p=0.23)$.

Time until discharge

The time until discharge did not differ between the rhDNase group and the placebo group (geometric mean (SE) 36.9 (1.2) vs 33.9 (1.2) h; mean difference 0.92 (95\% CI 0.55 to1.54), $\mathrm{p}=0.75)$.

\section{Duration of oxygen supplementation}

The proportions of children requiring oxygen supplementation to maintain a haemoglobin saturation $\geqslant 93 \%$ were similar in both groups over time (fig 4). The geometric mean (SE) time of

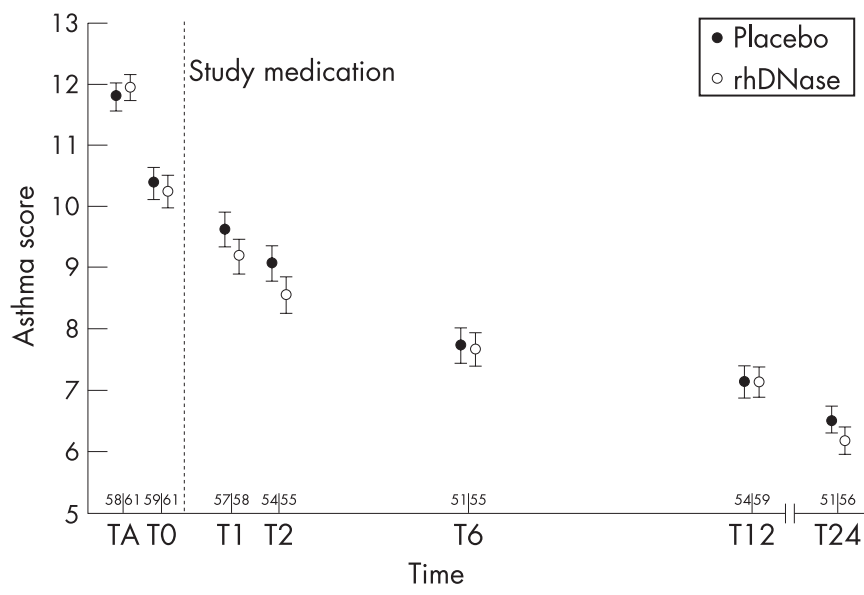

Figure 3 Mean asthma scores during study. TA, arrival at the emergency department; TO, before the second dose of bronchodilators and the subsequent single dose of study medication. Study medication was administered a median of $0.5 \mathrm{~h}$ after the assessment of the asthma score at T0. The asthma scores at T1, T2, T6, T12 and T24 were assessed at 1, 2, 6, 12 and $24 \mathrm{~h}$ after nebulisation of the study medication, respectively. Data given are ANOVA estimates (with standard errors). At all time points the number of patients in each treatment group for whom an asthma score was available is noted above the horizontal axis. $p$ Values for differences between study arms at the various time points are all $>0.20$.

oxygen supplementation did not differ; for both groups it was $28.3(1.2) \mathrm{h}(\mathrm{p}=0.99)$.

\section{Co-interventions}

Overall, there was no difference between the two groups in the number of treatments with nebulised bronchodilators given in the first $24 \mathrm{~h}$ during the hospital stay. Children in the rhDNase group received a median number of 7.0 (IOR 5.5-11.0) nebuliser treatments compared with 8.0 (IOR 6.0-10.0) in the placebo group $(p=0.81)$. In the subgroup of children who were discharged within $24 \mathrm{~h}(\mathrm{n}=30)$, the number of nebuliser treatments did not differ between the rhDNase and placebo

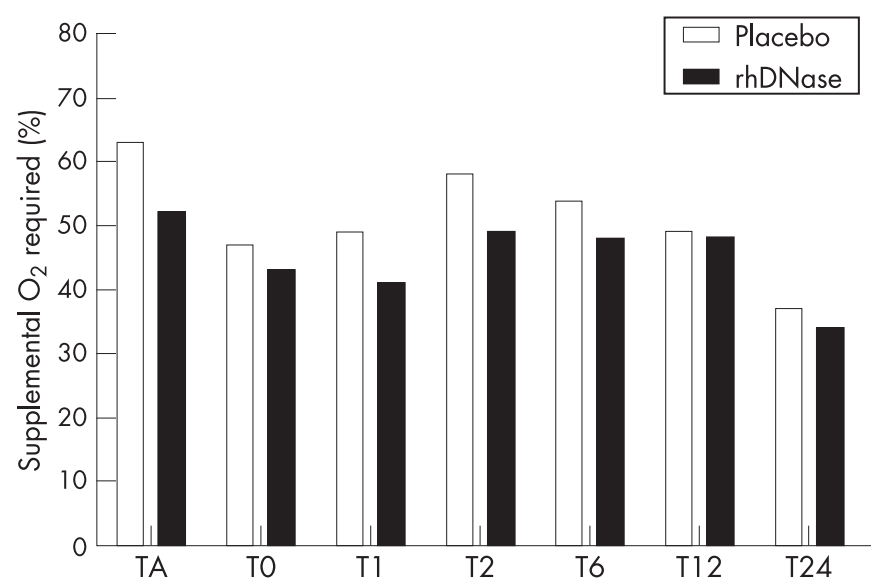

Figure 4 Need for supplemental oxygen during the first 24 h. Patients (\% of total) requiring supplemental oxygen to maintain a haemoglobin saturation of $\geqslant 93 \%$. TA, arrival at the emergency department; T0, before nebulisation of the second dose of bronchodilators and the subsequent single dose of study medication; T1, T2, T6, T12 and T24, 1, 2, 6, 12 and $24 \mathrm{~h}$ after nebulisation of the study medication, respectively. 
group (2.0 (IOR 0.0-5.3) and 2.5 (IOR 0.0-7.0), respectively, $\mathrm{p}=0.40)$.

Prednisolone was administered to $90 \%$ of all children (55 of 59 in the placebo group and 53 of 61 in the rhDNase group). Twelve patients did not receive a course of systemic steroids (5 were discharged home from the emergency department after their symptoms had resolved following the dose of study medication).

\section{Safety data}

One child had a transient desaturation with an increase in dyspnoea and tachypnoea directly after the initiation of the nebulisation with rhDNase, which resolved quickly after the nebulisation was stopped. Hoarseness was reported in two children (one in each group).

Asthma scores for 27 children were higher (worsened) $1 \mathrm{~h}$ after nebulisation of the study medication compared with baseline (12 children in the rhDNase group vs 15 in the placebo group, $\mathrm{p}=0.47)$.

\section{DISCUSSION}

We report the first randomised double-blind controlled trial of nebulised rhDNase in children (aged 2-18 years) with an acute asthma exacerbation. The findings show no evidence to suggest that nebulisation with the mucolytic rhDNase alleviates symptoms in children brought to the emergency room for moderate to severe acute asthma. We thus must reject our hypothesis that rhDNase is an effective additional treatment for children with acute asthma. This was based on the important role of mucus plugs in the pathophysiology of acute asthma, ${ }^{2}{ }^{3}$ and the finding that the DNA content is increased in the mucus of patients with acute asthma. ${ }^{6}$

To date, only case reports have suggested a benefit from rhDNase in children with status asthmaticus unresponsive to conventional treatment, ${ }^{10-13}$ and in children with acute severe asthma treated at the emergency department. ${ }^{11}$ Intervention with rhDNase, administered endotracheally or by means of a bronchoscope, was safe and improved ventilator settings ${ }^{12}{ }^{13}$ and arterial blood gas values ${ }^{13}$ and resolved atelectasis ${ }^{10}{ }^{12}$ in children receiving intensive care. Nebulisation of rhDNase in three children brought to the emergency department improved lung function parameters, the effectiveness of coughing and resolved atelectasis. ${ }^{11}$

There may be several explanations for the lack of effect of rhDNase in our study. First, the children might have had relatively mild disease with too little mucus plugging for rhDNase to be effective. Indeed, although all selected children had a moderate to severe asthma exacerbation and required at least two doses of bronchodilators, only four children required intensive care treatment. However, a subgroup analysis of children with an asthma score of at least 12 points after their first bronchodilator dose also could not demonstrate an effect of rhDNase. Because this analysis is underpowered $(n=35)$, definite conclusions about the effect of rhDNase in severe acute asthma cannot be drawn. We cannot exclude the possibility that rhDNase might have been effective in children with a more severe asthma exacerbation and/or atelectasis, or in those requiring admission to the intensive care unit. A separate study is needed to answer this question. In earlier case reports rhDNase was administered to children with a severe asthma exacerbation who also had atelectasis. We had no information about the presence or severity of atelectasis in our population because it was not considered necessary or ethical to perform two chest radiographs during treatment at the emergency department.

A second explanation might be that the amount of DNA present in the mucus was too low for rhDNase to be effective. The average DNA content of mucus in patients with stable asthma is higher than that in healthy controls (7.1 vs $3.6 \mu \mathrm{g} /$ $\mathrm{ml}) .{ }^{15}$ Even higher levels were found in patients with an asthma exacerbation $(0.5 \mathrm{mg} / \mathrm{ml}){ }^{6}$ The DNA content of mucus in patients with asthma is much lower, however, than in those with cystic fibrosis $(3-14 \mathrm{mg} / \mathrm{ml})^{16}$ in whom the beneficial effects of rhDNase have clearly been documented. ${ }^{9}$

A third explanation could be suboptimal lung deposition of rhDNase in children with bronchial obstruction, resulting in deposition of rhDNase mainly in the more central airways ${ }^{17}$ and not reaching the peripheral airways. To compensate for suboptimal deposition, patients received a dose of $5 \mathrm{mg}$ (twice the dose used as maintenance treatment in patients with cystic fibrosis). Arguably, it might have been more effective to administer the study medication immediately on arrival in the emergency department or following the first dose of bronchodilators rather than after the second dose, or to use repeated nebulisations of study medication instead of one. However, we think that other timing or dosing frequency would not change the results, since neither the symptom scores at any time points nor any of the secondary end points differed between the groups. Moreover, a single dose of rhDNase has an effect lasting many hours. ${ }^{18}$

Finally, as diagnosing asthma in preschool children is difficult, part of our study population might have had "exclusive viral wheeze" and not asthma. The exact role of mucus plugging in the pathophysiology of airway obstruction in children with "exclusive viral wheeze" has not been investigated to our knowledge. Our study focused on current emergency clinical practice which does not take into account the child's asthma phenotype.

Most of the participating hospitals routinely admitted children with an acute asthma exacerbation who required at least two doses of nebulised bronchodilators. It was not therefore meaningful to assess the effect of rhDNase on the admission rate. Even if a longer period of observation in the emergency room had been possible, we probably would not have found a positive effect of rhDNase on the admission rate since the decision to admit a child is based on the symptoms and we found no significant effect of rhDNase on the asthma score over time.

In this study the administration of rhDNase in acute asthma appeared to be safe. It was stopped in one case of temporary desaturation with an increase in dyspnoea and tachypnoea directly after the start of nebulisation. The mechanism of this desaturation is unclear, but we speculate that it might have been caused by the child's inability to clear mucus effectively after quick liquefaction by rhDNase.

Because our study population reflects the population of children with acute asthma treated in the emergency rooms of district and tertiary care hospitals, our results can be generalised to the large majority of children with a moderate to severe acute asthma exacerbation. Further studies on the effect of rhDNase in children with acute asthma requiring intensive care or with large atelectasis are still needed.

In conclusion, our study shows that a single dose of nebulised rhDNase in addition to nebulised bronchodilators and systemic steroids is not effective in the treatment of children with moderate to severe acute asthma. 
Acknowledgements: The authors thank the children, their parents and the staff of the eight participating centres.

Funding: Roche BV, The Netherlands provided an unrestricted grant for this study and financed the study medication. Pari GmbH, Germany donated the nebulising equipment. The study sponsors were not involved in the study design; in the collection, analysis and interpretation of data; in the writing of the report; and in the decision to submit the paper for publication.

Competing interests: None.

\section{REFERENCES}

1. Global Initiative for Asthma (GINA). Pocket guide for asthma management and prevention in children. 2006. www.ginasthma.org.

2. Wark PA, Gibson PG. Asthma exacerbations. 3: Pathogenesis. Thorax 2006;61:909-15.

3. Kuyper LM, Pare PD, Hogg JC, et al. Characterization of airway plugging in fatal asthma. Am J Med 2003;115:6-11.

4. Rogers DF. Airway mucus hypersecretion in asthma: an undervalued pathology? Curr Opin Pharmacol 2004:4:241-50.

5. Picot R, Das I, Reid L. Pus, deoxyribonucleic acid, and sputum viscosity. Thorax 1978;33:235-42.

6. Fahy JV, Kim KW, Liu J, et al. Prominent neutrophilic inflammation in sputum from subjects with asthma exacerbation. J Allergy Clin Immunol 1995;95:843-52.

7. Shak S, Capon DJ, Hellmiss R, et al. Recombinant human DNase I reduces the viscosity of cystic fibrosis sputum. Proc Natl Acad Sci USA 1990:87:9188-92.

8. Shah PL, Scott SF, Knight RA, et al. In vivo effects of recombinant human DNase I on sputum in patients with cystic fibrosis. Thorax 1996;51:119-25.
9. Fuchs HJ, Borowitz DS, Christiansen DH, et al. Effect of aerosolized recombinant human DNase on exacerbations of respiratory symptoms and on pulmonary function in patients with cystic fibrosis. The Pulmozyme Study Group. N Engl J Med 1994;331:637-42.

10. Greally P. Human recombinant DNase for mucus plugging in status asthmaticus. Lancet 1995; 346:1423-4.

11. Puterman AS, Weinberg EG. rhDNase in acute asthma. Pediatr Pulmonol 1997:23:316-7.

12. Durward A, Forte V, Shemie SD. Resolution of mucus plugging and atelectasis after intratracheal rhDNase therapy in a mechanically ventilated child with refractory status asthmaticus. Crit Care Med 2000;28:560-2.

13. Patel A, Harrison E, Durward A, et al. Intratracheal recombinant human deoxyribonuclease in acute life-threatening asthma refractory to conventional treatment. Br J Anaesth 2000;84:505-7.

14. Qureshi F, Pestian J, Davis $\mathrm{P}$, et al. Effect of nebulized ipratropium on the hospitalization rates of children with asthma. N Engl J Med 1998;339:1030-5

15. Fahy JV, Steiger DJ, Liu J, et al. Markers of mucus secretion and DNA levels in induced sputum from asthmatic and from healthy subjects. Am Rev Respir Dis 1993;147:1132-7.

16. Potter JL, Spector S, Matthews LW, et al. Studies on pulmonary secretions. 3. The nucleic acids in whole pulmonary secretions from patients with cystic fibrosis, bronchiectasis, and laryngectomy. Am Rev Respir Dis 1969;99:909-16.

17. Laube BL, Swift DL, Wagner HN Jr, et al. The effect of bronchial obstruction on central airway deposition of a saline aerosol in patients with asthma. Am Rev Respir Dis 1986:133:740-3.

18. Green JD. Pharmaco-toxicological expert report Pulmozyme rhDNase Genentech, Inc. Hum Exp Toxicol 1994;13(Suppl 1):S1-42.

\section{Lung alert}

\section{Smoking-induced emphysema is an autoimmune process}

Emphysematous lung exhibits predominantly T helper type 1 (Th1) cells, but it remains unclear how tobacco induces Th1 immunity and the nature of relevant $\mathrm{T}$ cell antigens. This study explored the possibility that smoking induces an autoimmune response.

Isolated blood CD4+ T cells from patients with emphysema and controls were tested to see if a specific $T$ cell response could be elicited using lung-derived elastin or collagen peptides as antigens. In response to elastin peptides, only peripheral blood CD4+ T cells from individuals with emphysema ( $\mathrm{n}=36$ ) released interferon (IFN) $\gamma$ and interleukin (IL)-10 and proliferated, compared with controls $(n=27)$ and patients with asthma $(n=9)$. There was a significant association between the increase in T cell secretion of IFN $\gamma$ and IL-10 with disease severity, as assessed by CT-based quantification and pulmonary function testing. ELISpot analysis confirmed the presence of $\mathrm{B}$ cells secreting antibodies to elastin, but not collagen, in emphysematous lung. In addition, significantly fewer regulatory $T\left(T_{R}\right)$ cells were present in the lungs of subject with emphysema.

Based on these findings, the authors proposed that exposure to cigarette smoke induces secretion of proteolytic enzymes from cells of the innate immune system that liberate lung elastin fragments. In susceptible individuals this may initiate $\mathrm{T}$ and $\mathrm{B}$ cell-mediated immunity against elastin.

- Lee SH, Goswami S, Grudo A, et al. Antielastin autoimunity in tobacco smoking- induced emphysema. Nat Med 2007;13:567-9

\section{Chuan-Gee Choo}

Correspondence to: C-G Choo, Specialist Registrar, Newcross Hospital, Woverhampton, UK; chuangee@hotmail.com

Thorax 2008;63:146 